This is a preprint of a paper, which is currently under review. This version is (C 2020 Martin Skov.

\title{
Animal Preferences: Implications of Sexual Selection Research for Empirical Aesthetics
}

\author{
Martin Skov ${ }^{1,2^{*}}$ \\ ${ }^{1}$ Danish Research Centre for Magnetic Resonance, Copenhagen University Hospital \\ Hvidovre, Denmark \\ ${ }^{2}$ Decision Neuroscience Research Cluster, Copenhagen University Hospital, Denmark \\ *Corresponding author: Martin Skov, Danish Research Centre for Magnetic \\ Resonance, Hvidovre Hospital, Kettegaards Alle 30, DK-2650 Hvidovre, Denmark. \\ E-mail: martins@drcmr.dk
}




\begin{abstract}
The theory of sexual selection posits that sexual species make use of sensory preferences for physical traits and behavior displayed by potential sexual partners to inform mate choices. This suggests that the ability to compute hedonic liking for perceptual stimuli is widespread across biological taxa, have a long evolutionary history, and that the neurobiological processes involved in assigning liking to sensory objects may be conserved over this history. It remains unclear, though, to what degree specialized forms of hedonic evaluations found in humans, including aesthetic appreciation, share common computational principles with appraisals of sexual traits in other animals. Unfortunately, comparative work is very rare, and researchers in the fields of sexual selection and empirical aesthetics appear largely ignorant about each other's work. In this paper I review recent important findings from sexual selection research in animals that directly have bearing on current discussions in empirical aesthetics about how to understanding the nature and uniqueness of human aesthetic appreciation. I argue that many of the outstanding issues in empirical aesthetics can only be resolved by comparing sensory evaluation in humans with other forms of sensory evaluation in other species.
\end{abstract}

Keywords: preferences, sexual selection, evolution, sensory systems, reward circuitry 
For most of Western history beauty was simply assumed to exist. It was seen as residing in things, a quality exhibited by some objects by virtue of their ontological constitution (Tatarkievicz, 1972). Philosophers interested in beauty therefore saw their main task as explaining which essential properties confer beauty upon an object (Beardsley, 1974; Eco, 1986). The answer accepted by most thinkers contended that things were beautiful because they were organized in a particular way, their elements related to each other in a harmonic, proportional order (Tatarkievicz, 1972). This socalled "Great Theory of Beauty" (Tatarkievicz, 1972) reigned from the time of the ancient Greeks well into the seventeenth century.

Then, around 1700, philosophers such as Hutcheson, Hume, and Reid revolutionized the Western conception of beauty by making the argument that the source of beauty is not the ontological constitution of things, but the constitution of the human mind (Dickie, 1996; Kivy, 2003). We experience beauty not because certain object properties are beautiful, but because the human brain contains a specific psychological system-a "beauty sense"-that generates the feeling of beauty when certain mental conditions are met. As a result of this idea, the problem of beauty pivoted from a question of ontology to a question of psychology: what are the computational principles that generate beauty responses? A century later, this conceptual revolution was further compounded by the publication of The Descent of Man, in which Darwin argued that humans are not the only species to experience beauty (Darwin, 1871). Darwin not only proposed that other animals also assess beauty-when making choices regarding whom to mate with-but also suggested that these beauty preferences exist because of the functional purpose they serve. Rather than being bequeathed ex nihilo by God, the ability to experience beauty had evolved because experiencing selected forms of stimuli as beautiful facilitates sexual 
reproduction. Indeed, since species make mate choices under different environmental and physiological circumstances, Darwin reasoned that different species must find different things beautiful. Thus, not only is beauty a species-specific psychological response to sensory input, the nature of this response is determined by the species' particular evolutionary history.

All modern scientific efforts to understand the phenomenon of sensory liking essentially take their departure from these two seminal ideas. Thus, to this day, empirical aesthetics and neuroaesthetics continue to be dominated by research attempting to work out the computational principles of how humans come to like certain stimuli in certain contexts. Meanwhile, biologists and evolutionary psychologists seek to understand why different species prefer different sexual traits. Yet, while most researchers investigating sensory liking recognize that the question of how and the question of why are two sides of the same coin, many academic traditions remain focused on only one of them. This is certainly true in the case of empirical aesthetics and sexual selection. Empirical aesthetics and sexual selection research ostensibly investigate the same scientific problem-what makes an animal prefer certain sensory stimuli to others - but only rarely come into any meaningful kind of contact, and seem mostly ignorant of findings produced by the other field.

Is this a problem? I think it is. By limiting its purview to the study of human liking responses, often exclusively in the context of cultural objects, and eschewing adaptive liking in other species, contemporary empirical aesthetics has effectively become married to a specific set of assumptions, especially the idea that human aesthetic liking is disinterested and emotionally special (Skov, 2019a; Skov \& Nadal, 2019). These assumptions depress the empirical scrutiny of a possible continuity between "human" and "animal" aesthetics, and promote ideas for which we have no 
actual evidence, especially the notion that aesthetic preferences are non-utilitarian (Skov \& Nadal, 2020). Sexual selection, on the other hand, often views sensory liking as a mere gateway to the more interesting question of how evolution come to select preferred traits, ignoring the problem of how preferences are in fact generated by the brain. This approach often leads to the assumption that it is possible to understand "psychological adaptations" without recourse to neurobiological mechanisms: "psychological adaptations are characterized in functional evolutionary terms, i.e., by the kind of information they are designed by selection to process rather than in terms of neurophysiology or neuroanatomy" (Thornhill, 2003, p. 14). The focus of sexual selection studies should, therefore, not be on the mechanics of preference making, but on "understanding the phenotypical design and thus the forces of selection responsible for adaptation" (Thornhill, 2003, p. 13). However, ignoring proximate causes also risks imputing function to "animal" liking that may be unwarranted, including denying non-human species the ability to engage in liking behavior that can be seen as complex or "aesthetic".

Luckily, in recent years an increasing number of researchers in both empirical aesthetics and sexual selection have begun to forge a greater integration of the two fields, bringer the questions of how and why into closer contact. A great example of this rapprochement is the publication of two recent books, Richard Prum's The Evolution of Beauty (2017), and Michael Ryan's A Taste for the Beautiful (2018). Both Prum and Ryan are prominent scientists in the field of sexual selection who have worked for decades on the topic of sexual preferences and the role they play in mate choice-Prum primarily in birds, Ryan mostly in frogs. In both books, Prum and Ryan argue that animal sexual preferences should be viewed as a form of aesthetic appreciation, continuous with the kind of human sensory liking studied by empirical 
aesthetics. Indeed, neither Prum nor Ryan shy away from speaking of animals as in fact experiencing states of beauty while forming preferences about which suitor to mate with.

Together, the two books by Prum and Ryan provide a timely introduction to ideas and research associated with sexual selection that hold a number of important implications for how theories in empirical aesthetics conceive of aesthetic appreciation and its functional purpose. In this paper I use their survey of behavioral and neuroscientific findings as a jumping-off point to discuss how the study of sexual preferences in non-human animals can help us improve our understanding of what of what a sensory "preference" really is: why preferences exist, where they come from, and how they are generated by different brains in different species. I first recapitulate the most outstanding empirical findings produced by recent sexual selection research, and then, in the last section, discuss how this body of work impact current debates about the nature of sensory evaluation in empirical aesthetics and neuroaesthetics.

\section{Mate Choice and Preferences}

First, what is sexual selection the study of, and how does it involve the phenomenon of sensory evaluation?

In brief, sexual selection can be defined as the "differences in reproductive success caused by competition for access to mates" (Andersson, 1994, p. 3). Darwin introduced the concept in The Descent of Man, as a companion to his concept of natural selection. Where natural selection describes the process of selection for genes that enhance the chance of an organism's survival in a specific environment, sexual selection concerns the process of selection for traits and behavior that increases the 
chance of access to procreation (Andersson \& Simmons, 2006; Jones \& Ratterman, 2009). In Darwin's own words, sexual selection “depends on the advantage which certain individuals have over other individuals of the same sex and species, in exclusive relation to reproduction" (Darwin, 1871, part 1, pp. 254-255).

Modern biology has identified several factors that can increase an individual's "advantage over other individuals" with respect to mating success (Kuijper, Pen \& Weissing, 2012). For example, phenotypic traits may help the individual outcompete other conspecifics for access to mates. In many species males evolve armaments that help them battle other males for access to females. Reproductive success is also affected by the evolution of female reproductive proteins that facilitate sperm-egg recognition, thus influencing the success of fertilization postcopulation (Good \& Nachman, 2005; Kuijper, Pen \& Weissing, 2012). The most important factor, though, that regulates access to reproduction is the choices individuals make about who to mate with. These choices turn out to be based on assessments of how attractive or likable physical traits and behavior exhibited by members of the opposite sex are. Traits and behavior that find favor with the choosing sex will be selected for by evolution.

Why does sexual reproduction depend on mate choices? Why do not all species simply allow any individual access to copulation? This is an interesting question that does not, as far as I know, have a definitive answer. As it so happens, not all biological taxa do rely on mate choices (although almost all plants and animals do), and most species that evolve sexually selected traits appear to exhibit only a very limited number of traits and behaviors (Wiens \& Tuschhoff, 2020). It remains unclear why this is case, although sexually selected traits seem more abundant in species with intense competition for access to reproduction, suggesting that certain conditions must 
be met for mate choice to evolve as a mechanism of sexual selection (Wiens \& Tuschhoff, 2020).

The generally accepted answer appears to be that mate choices derive from the fact that, as a matter of biology, individuals have different interests and concerns (Lane, 2010). In making mate choices, the individual comes to weigh these pros and the cons of reproduction. Most importantly, the two sexes have different reproductive concerns. Specifically, in most sexual species males evolve traits and behaviors designed to pursue sex with multiple partners, while females evolve psychological strategies geared at limiting their number of sexual partners. This leads to a pattern of courtship behavior where males (typically) attempt to convince females to allow them access to copulation, with females being selective about who among the many suitors she wants to procreate with. These different reproductive concerns have their root in the kind and number of gametes male and females produce (Ryan \& Jordan, 2017). As a rule, females produce few and large gametes, while males produce many and smaller gametes. For this reason, males have a greater chance of reproductive success if they mate with a large number of females, while females are better of pursuing strategies that secure the quality rather than quantity of mates. Specifically, females seek to mate only with those males that are most likely to help them secure healthy and successful offspring.

Hedonic preferences for physical traits or displayed behavior are cues females use to assess who among her choices meet her strategic concerns. This fact, in turn, puts pressure on males to evolve the kind of traits and behavior that will find favor with a female conspecific. Among the sexual traits females respond to when making mating choices are the production of sound (whining, chirping, bird song), emission of chemicals (pheromones, smells, aromas), motor displays (movement, dances, 
specific behaviors such as buildings nests), and visual body features, such as size, coloration, or ornamentation (Ryan, 2018). Crucially, individual males differ in how they embody such traits and perform such behaviors. This inter-individual variety allows females to make assessments as to which of the different instantiations of male courtship traits and behaviors they prefer most.

How can we know that the generation of preferences for traits is in fact the mechanism driving female mate choices? On this question, empirical sexual selection research has been instrumental in providing decisive evidence that females choose to mate with the males they find most attractive. Both Prum and Ryan detail a number of examples in their books that illustrate this body of research. For example, in the túngara frog-Ryan's species of choice—females prefer males that emit certain types of calls: so-called whines that are followed by so-called chucks. In experiments, Ryan has shown how female preferences vary with different call types (Ryan, 1990). For example, there is a $500 \%$ greater chance that a female will choose to mate with a male that emits a whine plus a chuck than one that emits only a whine. Females also vary in their preference for calls that have different numbers of chucks. Another example comes from Andersson's classic experiment manipulating the tail length of male windowbirds, making them either shorter or extra-long (Andersson, 1982). Counting nests, Andersson demonstrated that males with extra-long tails had increased mating success, whereas males with shortened tails had decreased mating success. Thus, females clearly generate different preferences for different forms of male traits, and are motivated to mate with the male that elicits the highest degree of preference.

In sum, the theory of sexual selection takes its departure from the fact that the two sexes of a species evolve different courtship strategies, the consequence of which is a selection process that determines who gets access to reproduction, and who does 
not. A key factor regulating access is the choices (mostly) females make about which male to mate with. These choices appear based on her preferences for available males' phenotypic traits and behaviors. Sexual selection, thus, suggests that animals employ some form of a appraisal system that produces sensory preferences that inform reproductive behavior.

\section{Models of Preference Evolution}

What do we know about the nature of such sexual preferences? There are four questions we especially want answered. First, we want to know why females prefer a specific trait rather than others. For instance, why do female windowbirds form preferences for male tails instead of, say, male beaks? Secondly, why do different versions of a trait elicit different degrees of hedonic value? Why do female windowbirds have a higher preference for longer tails? Third, how are preferences generated psychologically and neurobiologically? Are they processed unconsciously, or do they become consciously represented in the form of feelings? Are they genetically determined, or susceptible to learning and contextual modulation? Fourth, what are the evolutionary reasons specific trait-preference couplings become dominant in a species? In short, where do sensory preferences come from?

The theory most prevalent in contemporary neurosciences suggests that sensory preferences arise when perceptual representations of physical objects become associated with liking and wanting signals generated by nuclei located in the mesocortical reward circuit (Berridge \& Kringelbach, 2015; Pessiglione \& Lebreton, 2015; Skov, 2019b). Thus, for the female windowbird to generate a preference for certain male tails (1) her visual system must be able to first detect differences in light 
that represent male tails and their length, and (2) then relay this visual information to the reward circuitry where the resulting state of reward activity give rise to a variance in hedonic liking and wanting. This implies that the main question of sexual selection can be formulated as follows: what are the reasons the windowbird's brain evolved to associate tail representations with hedonic signals in the context of reproductive behavior?

Over the years, the latter question has been the subject of many intense debates. Several models have been proposed attempting to explain how genes coding for male traits can become associated with genes coding for female preferences. Of these, two models appear to have found most favor and empirical support, with a third model coming to recent prominence (Andersson \& Simmons, 2006; Cummings \& Endler, 2018; Kokko, Jennions \& Brooks, 2006; Kuijper, Pen \& Weissing, 2012; Ryan \& Johnson, 2017).

The first of these models posits that evolution of a female preference for a male trait is driven by the direct benefit expressing this preference has for the female's reproduction (Kokko, Jennions \& Brooks, 2006; Kuijper, Pen \& Weissing, 2012). Specifically, the model stipulates that if the choice resulting from a preference increases the chance of fecundity the frequency of the female's genotype should increase in the population (Grammer, Fink, Møller \& Thornhill, 2003; Kuijper, Pen \& Weissing, 2012; Ryan \& Jordan, 2017). Studies have identified several factors that help make a male trait directly beneficial to a female's strategic needs, including traits that indicates that the male is a suitable sexual candidate (i.e., male and a conspecific), is healthy, disease-free, strong, has access to resources, and is genetically different from the female (Ryan \& Jordan, 2017). 
The second model posits that female preferences for male traits evolve because of the indirect benefits they confer on fecundity. This type of co-evolution happens when a preference emerges and takes hold in a population. Males that exhibit the preferred trait will now have a mating advantage because they are chosen over those that do not, and as a consequence produce more "sexy sons" (offspring that also exhibit the preferred trait). This increased frequency of attractive traits in turn leads to an increased, future selection of genes associated with the original female preference, leading to a self-reinforcing co-occurrence of trait and preference (Kuijper, Pen \& Weissing, 2012). This model is also known as Fisherian runaway selection, after R.A. Fisher (1915).

Current consensus appears to hold that both direct and indirect benefits drive the evolution of trait-preference associations (Andersson \& Simmons, 2006; Cummings \& Endler, 2018; Kokko, Jennions \& Brooks, 2006; Kuijper, Pen \& Weissing, 2012; Ryan \& Johnson, 2017). The two models, however, have quite different implications for how we should conceive of the nature of sexual preferences.

Direct benefit models assume that preferences are selected for because they promote the choosing of males with "good" genes. This suggests that traits become preferred because they are honest indicators or signals of these good genes (Gangestad \& Scheyd, 2005). The implication of this view is that preferences for sexual traits track genetic or material benefits. For example, what explains apparent human preference for traits such as femininity, masculinity, symmetry, skin color, or averageness, is the fact that these traits signal health, complimentary genes, and sexual dimorphism (Fink \& Penton-Voak, 2002; Johnston, 2005; Little \& Jones, 2009; Little, Jones \& DeBruine, 2011; Puts, 2010; Rhodes, 2006). The indirect benefit model, on the other hand, allows for preferences to evolve without any such 
connection to indicator value. Instead, models such as Fisherian runaway selection assume that preferences emerge for non-adaptive reasons, and only select for male traits in later generations as mating with "sexy sons" becomes more prevalent.

Proponents of direct and indirect models have often been at odds, and the premise of Prum's book is very much his contention that Fisherian models of sexual preference have been unfairly rejected by mainstream evolutionary biology. He describes Fisherian models as having been de facto sidelined by proponents of direct benefit models, and casts his book as a defense of sexual selection seen as powered by “impractical" and "arbitrary" beauty, not by adaptation. To Prum this debate is crucial, because to choose either is to make a claim about the function of sexual preferences. In his view, the Fisherian model implies that preferences have no utilitarian value to the chooser, only "aesthetic value". They are purely "arbitrary" experiences of beauty for the "trait itself”. They are, in Prum's words, "mere attractive, or merely beautiful" (Prum, 2017, p. 60).

In reviews by colleagues, this characterization of Fisherian selection as unfairly suppressed, and Prum's way of interpreting sexual preferences, has come in for something of a drubbing (e.g., Borgia \& Ball, 2018; Patricelli, Hebets \& Mendelsohn, 2018). While parts of this critique seem fair, Prum is clearly right that some, if not all, researchers in sexual selection traditionally have favored an adaptionist explanation of the nature of sexual preferences: "Beauty experiences are unconsciously realized avenues to high fitness in human evolutionary history" (Thornhill, 2003, p. 9). "The general consensus is that mate choice is focused on phenotypic (and often genotypic) quality and sexual advertisement is basically about displaying phenotypic quality" (Ibid, p. 11). Certainly, the vast majority of experiments on human preferences for body traits has sought to link trait liking with 
evidence of reproductive quality (Johnston, 2005; Little \& Jones, 2009; Puts, 2010; Rhodes, 2006). Not surprisingly, as a consequence, preferences for face or body traits have often been described as universal (Langlois et al., 2000), based in inherited genes (Grammer, Fink, Møller \& Thornhill, 2003; Gangestad \& Scheyd, 2005), and as unfolding reliably in all contexts upon exposure to the preferred trait (Gangestad \& Scheyd, 2005; Fink \& Penton-Voak, 2002).

\section{Sensory Bias}

The indirect and direct models are by far the two most influential models of how trait-preference associations can evolve. They are, however, not the only ones. As noted above, there is a third model, first proposed in the early 1990s, which has become increasingly prominent over the last 20-30 years. Named the sensory bias (Ryan \& Cummings, 2013) or sensory drive (Cummings \& Endler, 2018) model, it suggests that sensory preferences can evolve as responses to non-sexual aspects of the environment, and then become co-opted by the neurobiological system underlying sexual choice. Ryan has been one of the developers of this model, and his book essentially functions as a popular introduction to this fascinating body of work.

A good example of sensory bias evolution is the way preferences in female guppies for orange ornamentation appears to derive from a change in photopigment sensitivity conditioned by their foraging for orange fruit (Rodd et al., 2002). Rodd and colleagues (2002) tested this hypothesis by presenting male and female guppies with poker chips differing in color. They found that the time spend inspecting orange chips predicted the strength of the female guppies' preference for orange coloration in males. To further test if a greater preference for orange coloration, prompted by 
enhanced exposure to orange food, also selects for male traits, John Endler \& Gemma Cole developed lines of guppies that had been exposed to either blue or red chips. In the two lines, subsequent generations evolved a preference for red or blue food. However, only in the line with an evolved preference for red food the males also evolved a greater amount of orange coloration compared to the males in the blue line (Cole \& Endler, 2016).

Studies like these demonstrate that females can apply sensory preferences that evolved in other contexts to that of mate choice. This allows males to tap into "hidden" preferences by evolving traits that match the female's already existing sensory biases. Experimenters have demonstrated how such preferences can transfer from a non-sexual context to a sexual context by artificially adding hitherto unknown traits to males in lab settings. For instance, when male Zebra finches are adorned with black or pink leg bands they become increasingly attractive to females (Burley \& Symanski, 1998), suggesting that the brain of the female Zebra finch is already equipped with a preference for pink and black. Similarly, Ryan and his colleagues played a wide assortment of sounds as part of the male túngara frog's courtship call and found that females were attracted to males associated with sounds not expressed by any living túngara frog (Ryan, Bernal \& Rand, 2010).

Empirical research into sensory biases makes it clear that sexual preferences not always evolve because the female brain adapts to male traits that signal direct benefits, or because of indirect processes. In many cases, sexual preferences arise because male traits evolve that match existing, non-sexual, sensory preferences. Evidence that sensory biases play a factor in sexual selection is by now overwhelming, at least for the visual and auditory modalities (see Cummings \& Endler, 2018, and Ryan \& Cummings, 2013, for reviews of this literature). Selection 
rooted in sensory biases has been found in fish, birds, mammals, and reptiles (Cummings \& Endler, 2018). Moreover, findings show that sensory biases result not only from the modification of perceptual processes (such as the selection for photopigments that allow the guppy to procure orange-tinted food). They also result from changes to cognitive processes, including the general ability to distinguish between extreme and normal traits, or the ability to avoid stimuli deemed negative to reproduction (Ryan \& Cummings, 2013). There are therefore good reasons to believe that a significant number of sexual preferences were selected for signals that cannot be characterized as honest indicators of mate quality.

\section{Fickle Preferences}

The different models for how preferences and traits can evolve to become associated also suggest different hypotheses about the way preferences are generated. Specifically, the direct benefit model assumes that female preferences track reproductive fitness. Therefore, as already noted, adherents to the direct benefit model often presume that preferences for adaptive traits are universal and independent of context. Evidence suggests that in many circumstances this is not true. In many species, if not all, female preferences are flexible: Depending on contextual conditions, females will sometimes choose to mate with suitors of inferior reproductive value, or even change preference from "optimal" traits to other traits altogether.

An example that illustrates such "fickleness" in the generation of sexual preferences comes from work done by Lynch and colleagues (2005) on the túngara frog. A túngara female must mate during the night otherwise she will loose all her 
ovulated eggs. Lynch found that as the female comes up upon the time where she looses her eggs she changes approach from calls she usually finds attractive to calls she earlier in the night would find unattractive (Lynch et al., 2005). This lowering of standards turns out to be accompanied by an increase in estrogen levels (Lynch et al., 2006). Another important example of how sexual preferences are flexible is found in the way females often copy choices made by other females. In many species, females will change preference from a highly-preferred male to a less-preferred males if the latter is seen as courted by other females. For example, as shown by Dugatkin (1992), if a female guppy is placed in an aquarium surrounded by two males in different compartments, she normally seeks out the male with most orange ornamentation. However, if another female is then placed in the compartment with the less preferred male, the test female will then reverse her initial preference and seek out the male with less orange.

Research has identified a host of conditions able to modulate the way sexual preferences are generated. In addition to time and social conformity, some studies have found preferences for one version of a trait over another to be affected by the presence of a decoy or anchor, that is to say a different, third option. For example, Lea and Ryan (2015) demonstrated that female túngara frogs will switch preference from a male call, B, that is preferred to another call, A, when directly compared, if a third call, $\mathrm{C}$, inferior to both $\mathrm{A}$ and $\mathrm{B}$, is introduced. In sum, the way sexual preferences are computed appear to be influenced by both internal and external conditions, including endocrinological state, availability of mate options, risk, presence of competitors and predators, and other factors that have a bearing on reproduction (Kirkpatrick, Rand \& Ryan, 2006; Ryan \& Jordan, 2017). In Ryan's 
words fickle preferences "are common and might even be the rule rather than the exception" (Ryan, 2018, p. 126).

\section{Neurobiology of Sexual Preferences}

Interestingly, primate and rodent research suggests that flexibility is build into the computational principles underlying the generation of hedonic responses to sensory representations (Skov, 2019a, 2019b; Skov \& Nadal, 2019). Specifically, studies suggest that value signals in the reward circuit are modulated by signals from other neural systems (Berridge \& Kringelbach, 2015; Pessiglione \& Lebreton, 2015; Seymour \& McClure, 2008). These include signals from interoceptive systems signaling the homeostatic state of the internal organism, hormones such as gonadal sex hormones or stress hormones, or signals emanating from cognitive systems that can reflect beliefs, expectations, or other processes relevant to the control of behavior (Skov, 2019b). As a result, hedonic liking for sensory representations appear to be modulated by neural processing that goes beyond stimulus-triggered activity in perceptual systems (Skov \& Nadal, 2019).

Do sexual selection studies find a similar flexibility in the computational factors that determine sexual preferences in concrete situations? Yes. For instance, in most species courtship is highly regulated by endocrinological processes. Without appropriate levels of hormones such as testosterone or androgen males in most species will not initiate breeding behavior. Similarly, a female's receptiveness to male courtship display is conditioned by levels of estrogen and progesterone. Importantly, studies find that hormone levels also influence preference response to sexual signals. For example, female ringdoves ignore male courtship displays when reproductive 
endocrine levels are low, but become receptive when follicle-stimulating hormones increase in level (Cheng, 2008). Similarly, as noted, female túngara frogs become more permissible of less attractive males as they near ovulation (Lynch et al., 2005), and this modulation of preference can in fact be artificially induced by injecting female túngara frogs with high doses of human chorionic gonadotropin, a ligand that cause increased gonadal hormone production (Lynch et al., 2006).

Thus, the state of reproductive hormones plays an important role in modulating preferences and behavioral responses to courtship signals. This means that such percepts are more or less enticing to the female chooser depending upon her reproductive condition. How is this accomplished mechanistically? First, changes to the endocrine state should modulate perceptual responses to signals emitted by conspecifics, and especially courtship signals emitted by the male courter (Maney, 2013). This is in fact also what researchers find to be the case. For example, neural activity in auditory areas of female songbirds is modulated by the state of reproductive hormones such as estradiol, affecting saliency of conspecific signals (e.g., Maney et al., 2008; Lattin, Stabile \& Carson, 2017; Vélez, Gall \& Lucas, 2015). Secondly, variance in endocrine state should also affect how sensory signals give rise to neural activity in the mesolimbic reward circuit. Empirical findings also support this idea. For instance, Earp and Maney (2012) found that male songs express the early gene product Egr-1 in reward structures such as nucleus accumbens, ventral tegmental area, and the caudate nucleus when injected with doses of estradiol, suggesting that reproductive hormones boost processes associated with generating incentive salience (Diekhof, 2018; Maney, 2013, Sakaki \& Mather, 2012; Yoest, Quickley \& Becker, 2018). 
Together, behavioral findings and neurobiological experiments support the view that while evolution can link specific perceptual representations to liking and wanting signals, such that encounter of such traits will preferably elicit approach behavior, contextual circumstances can affect how this process unfolds and sometimes downgrade preferences for adaptive traits. Intriguingly, this picture appears very much in accordance with our understanding of how hedonic values and preferences are computed in other domains as well.

\section{Implications of Sexual Selection Research for Empirical Aesthetics}

As research enterprises empirical aesthetics and sexual selection are characterized by several methodological and theoretical differences. Empirical aesthetics is mainly pursued by psychologists and neuroscientists who work with human subjects, and is interested in how preferences form for cultural objects. This type of appraisal, often called aesthetic appreciation, is predominantly thought to consist of the production of "disinterested", self-contained, emotional responses to such objects (Skov, 2019a). Thus, in the context of empirical aesthetics sensory preferences are conceived of as distinct "aesthetic" states that are specific to Homo sapiens. In contrast, sexual selection is predominantly studied by behavioral ecologists and evolutionary biologists who are mainly interested in non-human animals. The main objective of most sexual selection research is seeking an understanding of how trait-preference associations evolve, and how they motivate reproductive behavior. For this reason, in the context of sexual selection sensory preferences are generally thought of as adaptive appraisals that motivate behavior. 
The difference in aims and methods distinguishing empirical aesthetics and sexual selection is partly determined by a difference in the type of problems that animate the two fields, but it is also informed by the assumptions we have about the kind of sensory preferences humans and other animals engage in. The sexual preferences non-human animals generate in the context of reproduction are believed to exist to guide adaptive behavior, and are therefore thought to reflect inherited, regulatory concerns. They are emotional in nature, but probably not experienced in a conscious, phenomenological manner (LeDoux, 2012). In contrast, human aesthetic preferences are considered non-adaptive, generated during psychological events where sensory qualities are appraised for "their own sake". They may rely on some inherited affinities for certain sensory features, but are also supposed to involve subjective, cognitive processes (i.e., meaning) to a high degree. Aesthetic preferences are therefore rarely considered reflective of regulatory concerns. They are definitely believed to be experienced consciously in the form of phenomenological feelings. Indeed, partaking in such affective states is generally considered to the main purpose of human aesthetic preferences.

Whether these intuitions about human and animal sensory preferences are correct remains to seen, though. We currently have little empirical evidence that speaks to any presumed differences in the nature of animal sexual preferences and human aesthetic preferences. Particularly, there are precious few comparative studies that have investigated possible differences in how different nervous systems generate sensory preferences, and what functional purposes such differences may serve. If we want to understand what, if anything, is specific about the capacity for human aesthetic evaluation, we must contrast it with other forms of valuation as they appear in other species. Sexual preferences provide an important case for such a comparison. 
I here highlight four issues of current theoretical interest where models of human aesthetic evaluation will benefit greatly from the incorporation of insights into animal sexual preferences.

Are "Animal" and "Human" Preferences Continuous?

The hypothesis that aesthetic appreciation constitutes a special kind of sensory appraisal, characterized by a distinct set of functional and neurobiological properties, looms large in contemporary debates about how to understand findings in empirical aesthetics and neuroaesthetics. Together with Marcos Nadal I have myself argued that there is little clear evidence that the kind of sensory appraisals we call aesthetic appreciation is categorically different from other types of sensory appraisals in humans (Skov, 2019a; Skov \& Nadal, 2019, 2020). It still remains true, though, that humans engage in types of sensory appraisal that are specific to us as a species, including appraisals directed at sensory objects that can be though of as possibly "abstract", "cultural", or "non-utilitarian". It is clear that a major part of the Umwelt we inhabit consists of human constructed objects with no immediate relevance for our survival. We routinely evaluate these parts of our environment for their hedonic value, raising the question if some aspects of the neural system of sensory valuation have undergone modification in order to enable us to do so?

While any answer to this question would be premature, it is striking that evidence from sexual selection research strongly suggests that preferences elicited in nonhuman animals for sexual traits result from comparable computational processes as those underlying human preferences for cultural objects. For example, both forms of sensory valuation involve a transfer of information from sensory systems to value signals located in the reward circuitry: Whether the sensory object being evaluated is 
a painting by Van Eyck or coloration on the body of the male guppy liking emerges when certain patterns of neural activity in reward structures assign a measure of hedonic value to perceptual representations. Furthermore, many of the computational principles that determine sensory liking appear to be conserved across species, including anatomical organization of the reward circuitry, neurochemistry, and the function of value signals. Hence, prediction of upcoming reward following exposure to a sensory cue appears to depend on the release of dopamine in human music as well as in bird songs used as sexual display (Earp \& Maney, 2012; Gold et al., 2019; Maney, 2013; Salimpoor et al., 2011).

The fact that aesthetic evaluation of cultural objects share basic computational principles with the evaluation of sexual traits - as well as evaluation of food and drink items (van den Bosch et al., 2014) - suggests that different kinds of hedonic valuation tap into a common neurobiological system that is remarkably conserved over evolutionary time. At the same time evolutionary logic informs us that this system must be adapted to unique environmental demands in individual species. Work on sensory biases in sexual selection demonstrates that one way such adjustments can take place is through changes to sensory systems that allow a species to form preferences for objects present in its habitat. Other changes may include specific ways for cognitive processes to modulate reward activity, or indeed modifications to the anatomy and function of the reward circuitry itself. It is quite possible that hominin evolution has enabled a greater integration of cognitive representations and hedonic valuation in humans (Pessoa, Medina, Hof \& Desfilis, 2019), or facilitated an enhanced conscious representation of affective states (Paul et al., 2020), and that such tweaks have endowed Homo sapiens with its own unique set of sensory pleasures, but it remains unclear if any possible evolutionary changes can be attributed specifically 
to a need for an aesthetic evaluation of the emerging environment of human culture. As a field, we desperately need comparative data in order to assess to what degree aesthetic appreciation owes anything to recent evolutionary changes, or if it predominantly relies on neurobiological processes inherited from our ancestors.

\section{Where do Preferences Come From?}

The vast majority of experimental work in empirical aesthetics is focused on understanding what kind sensory stimuli humans like. From studies collecting preference measures for variations of stimulus features we have learned at lot about the perceptual conditions that elicit pleasure and displeasure. Furthermore, with neuroimaging we have also gained a basic understanding of the neurobiological processes involved in generating hedonic liking for specific sensory experiences (Skov, 2019b). What has received far less attention is the question of why humans respond in this way to the sensory world we are equipped to perceive. How does a given perceptual representation become associated with an accompanying pleasure response?

Evolutionary theory stipulates that a stimulus becomes liked because, over time, engagement with it has proven advantageous to the survival of the organism. The pleasure evoked by perception of the stimulus serves to reward repeated engagement with valuable parts of the environment. Yet, as we have seen, when it comes to understanding the mechanics of how neurobiological processes actually change to accommodate this evolutionary logic the answer is far from trivial. At least in the domain of sexual preferences, evidence seems to suggest that a perceptual trait can become liked due to different forms of evolutionary conditions. 
A central insight uncovered by sexual selection is the fact that novel sexual preferences can emerge because changes have occurred to the sensory system. This finding underscores an important evolutionary lesson: that biological organisms can only come to form preferences for the parts of the surrounding world they can perceive, and that these parts themselves are a result of the individual species' evolutionary history. For example, the female túngara frog's preference for male calls only exists because her auditory system happens to match the auditory properties of these calls. Because of its specific evolutionary history the túngara frog is equipped with two hearing organs, the amphibian papilla (AP) and the basilar papilla (BP). The organization of these two organs enables the perception of sounds within specific auditory frequencies ranging below and above 1,500 Hz (Ryan, 2018). Specifically, the AP responds preferably to sounds around $700 \mathrm{~Hz}$, while the BP is tuned to sounds around 2,200 Hz. These two peak frequencies match the two call types emitted by male túngara frogs: the whine, with a dominant frequency of $700 \mathrm{~Hz}$, and the chuck, with a dominant frequency of $2,500 \mathrm{~Hz}$ (Ryan, 2018). The auditory preferences the túngara frog is able to generate are constituted by these perceptual conditions.

Work on sensory biases raises the possibility that hedonic liking can become associated with perceptual representations for one evolutionary reason, only to be later adopted for other purposes. Liking for yellow can evolve first in the context of foraging and later become rewarding in the context of mating behavior. It goes without saying that the implications of this finding for empirical aesthetics could be profound. Following Kant it has been assumed by most thinkers that a defining feature of human aesthetic evaluation is the disinterested character of the hedonic liking it produces. In the context of modern neuroaesthetics this idea has lead to an unresolved discussion about how we should conceive of the hedonic values the 
human reward circuitry elicits for sensory objects with no apparent biological value (Chatterjee \& Vartanian, 2014; Skov, 2019a; Skov \& Nadal, 2020). The existence of sensory biases in the domain of sexual preferences suggests that this dilemma may not be as vexing as it has been made out to be. Rather, aesthetic preferences may turn out to be another domain of sensory valuation where perceptual representations that became associated with pleasure in one context have been co-opted for a different behavioral purpose.

\section{Universal or Contextual Preferences?}

Does a sensory preference reflect a universal rule, or is it modulated by contextual circumstances? This is another fundamental question in empirical aesthetics - one that can trace its importance back to eighteenth century debates about whether or not taste responses can be correct or "good". As discussed, in contemporary science it also bears on the question of how sensory preferences are established: if we are programmed to like sensory objects that helped our ancestors to survive. Indeed, to conceive of sensory preferences as automatic and stereotypic responses to releasing stimuli, or as a contextual answer as to which behavioral action will serve the organism best with respect to current physiological and environmental circumstances, entail two very different models of how sensory valuation works.

Sexual selection experiments provide an important testing ground for this question. Preferences for sexual traits are considered one of the primary reinforcers that may have a genetic basis. As noted, psychologists studying sexual preferences in humans have often based their work on the assumption that certain traits must be universally liked (Gangestad \& Scheyd, 2005; Grammer, Fink, Møller \& Thornhill, 2003; Johnston, 2005; Langlois et al., 2000). Over the last two decades experiments 
have increasingly the probed the way different brains implement mating decisions, casting light on how hedonic liking is in fact computed during mate choice events (Ryan, 2018; Ryan \& Jordan, 2017). Evidence from these experiments strongly imply that, even in the case of adaptive traits, sexual preferences are determined not just by the activation of perceptual representations, but also by contextually relevant factors that are represented by a number of other neural processes. For instance, experiments have shown that different combinations of whines and chucks emitted by male túngara frogs elicit different types of co-activation involving nuclei in the auditory cortex, reward circuitry, and motor regions (Hoke et al., 2004). Similar patterns of coactivation, integrating contextual information, are found in other domains of behavioral decision-making (Berridge \& Kringelbach, 2015; Pessiglione \& Lebreton, 2015; Skov, 2019b). This mounting evidence has led to the formulation of computational models suggesting that not only must perceptual representations gain access to reward neurons in order to yield hedonic liking, but the way these nuclei respond to a given perceptual input is modulated by signals from interoceptive and cognitive regulation systems (Berridge \& Kringelbach, 2015; Pessiglione \& Lebreton, 2015; Skov, 2019a, 2019b; Skov \& Nadal, 2019). Furthermore, studies find that the way sensory information is filtered through different perceptual and cognitive mechanisms can imbue identical stimuli with different representational content that leads to variations in hedonic responses (Skov, 2019b). This fact explains how a female guppy can keep track of how attractive a male is to other females, in the process modulating her hedonic response to him. Finally, perceptual information prompts several different types of value signals, some generating pleasure, others incentive salience and wanting (Berridge, 2019; Berridge \& Kringelbach, 2015; Pessiglione \& Lebreton, 2015). It is still largely a mystery how these many processes 
interact not only to produce preference responses, but also to guide mate choices and behavior. Any convincing answer must triangulate investigations involving not only different species but also different domains of sensory valuation, including, prominently, sexual selection research.

\section{What is an "Aesthetic" Preference?}

Despite decades of empirical work, it remains unclear to what degree sensory evaluations across different species and functional domains should be considered a common biological phenomenon or specialized phenomena with different psychological and neurobiological characteristics. It is, for instance, often assumed that "sexual" preferences used to inform mate choices in animals are categorically different from "aesthetic" preferences exhibited by humans. However, while several possible differences have been invoked in support of this distinction-sexual preferences are adaptive, aesthetic preferences disinterested; human preferences for human objects are more complex or phenomenological distinct from animal preferences, etc. - too little is currently known about how they may differ from each other for us to be able to settle this question with any certainty.

It is intriguing to note that Darwin's process of developing the theory of sexual selection owed a lot to a consideration of contemporary aesthetic theories. As the historian Evelleen Richards has demonstrated in her book Darwin and the Making of Sexual Selection, Darwin both read and was influenced by philosophers such as Erasmus Darwin, Joshua Reynolds, David Hume, and Edmund Burke, as he worked on formulating the principles of sexual selection (Richards, 2017). Indeed, Richards convincingly argues that the intellectual impetus that led Darwin to consider sexual selection as an evolutionary mechanism in the first place was the classic aesthetic 
conundrum of taste: Why is it that different individuals like different sensory impressions? Darwin applied this "human" question to animals and tried to work out a mechanism that would explain how specific taste profiles emerge in different animal populations (Richards, 2017). In doing so, he explicitly assumed that taste in humans and animals would derive from the same biological principle of aesthetic evaluation, even if the particulars of what individual species like by necessity would differ.

As we have seen, Darwin's stance is today controversial, with some evolutionary biologists directly disavowing it. It is gratifying, though, to see influential scientists such as Prum and Ryan defend Darwin's view of animal sexual preferences as continuous with human aesthetic evaluation. Both are happy to talk about animals having aesthetic experiences, experiencing traits they prefer as beautiful, etc. While this stance has been met with criticism from other researchers, who fault especially Prum for confusing the use of concepts such as taste, beauty or desire in human aesthetics with that of animal preferences for sexual display (Patricelli, Hebets \& Mendelsohn, 2018), it is very important to realize, I think, that most of the arguments being employed in this debate hinge on subjective intuitions about what these concepts mean. For example, the degree to which one is willing to admit that animals experience traits as beautiful can hinge on whether or not one associate beauty with being non-adaptive. Such assumptions only take us so far, and should preferably be supplanted by empirical knowledge. This, in turn, can only come from a coordinated comparison of behavior and neurophysiology related to sensory valuation as it occurs in different domains and in different species. 


\section{Conclusion}

Sexual selection research represents one of the central scientific enterprises investigating the way sensory information becomes imbued with hedonic value during behavioral decision-making (here mate choice). Unfortunately, many in both empirical aesthetics and neuroaesthetics remain ignorant about the many important findings produced by the field of sexual selection that directly impact the way we conceive of sensory evaluation in humans. Here I have tried to briefly review some of the most important recent work in sexual selection in order to show how experiments on animal sexual preferences also illuminates the phenomenon of human aesthetic preferences. Specifically, similarities in the computational principles regulating neural process associated with animal sexual preferences and human aesthetic preferences suggest that, at a minimum, the latter is continuous with the former. Furthermore, studies demonstrating that stimuli that become rewarding under one set of selection pressures can be exploited by other behavioral domains indicate that the key to understanding the evolution of preferences for sensory objects lies in understanding the way sensory systems evolve to explore specific environments. What we think of as human aesthetic evaluation may conceivably be the co-option of hedonic liking for perceptual features and factors that originally evolved in the context of adaptive survival to help us navigate the cultural environment that began expanding in our species some 100.000 years ago. Perhaps counter intuitively, in order to understand whether or not human aesthetic appreciation constitutes an unique kind of sensory evaluation we must integrate the work we do in empirical aesthetics and neuroaesthetics better with work conducted in animal models. 


\section{References}

Andersson, M. (1982). Female choice selects for extreme tail length in a widowbird. Nature, 299, 818-20

Andersson, M. (1994). Sexual Selection. Princeton University Press.

Andersson, M., \& Simmons, L.W. (2006). Sexual selection and mate choice. Trends in Ecology and Evolution, 21, 296-302.

Beardsley, M. (1976). Aesthetics from Classical Greece to the Present: A Short History. University of Alambama Press.

Berridge, K.C. (2019). Affective valence in the brain: modules or modes? Nature Reviews Neuroscience, 20, 225-234.

Berridge, K.C., \& Kringelbach, M.L. (2015). Pleasure systems in the brain. Neuron, $86,646-664$.

Burley, N.T., \& Symanski, R. (1998). “A taste for the beautiful”: Latent aesthetic mate preferences for white crests in two species of Australian Grassfinches. The American Naturalist, 152, 792-802

Chatterjee, A., \& Vartanian, O. (2014). Neuroaesthetics. Trends in Cognitive Sciences, $18,370-375$.

Cheng, M.-F. (2008). The role of vocal self-stimulation in female responses to males: Implications for state-reading. Hormones and Behavior, 53, 1-10.

Cole, G.L., \& Endler, J.A. (2016). Male courtship decisions are influenced bylight environment and female receptivity. Proceedings of the Royal Society of London B, 283, 20160861.

Cummings, M.E., \& Endler, J.A. (2018). 25 years of sensory drive: The evidence and its watery bias. Current Zoology, 64, 471-484.

Darwin C. 1871. The Descent of Man and Selection in Relation to Sex. London: Murray

Dickie, G. (1996). A Century of Taste. Oxford: Oxford University Press.

Diekhof, E.K. (2018). Estradiol and the reward system in humans. Current Opinion in Behavioral Sciences, 23, 58-64.

Dugatkin, L.A. (1992). Sexual selection and imitation: Females copy the mate choice of others. The American Naturalist, 139, 1384-1389.

Earp, S.E., \& Maney, D.L. (2012). Birdsong: is it music to their ears? Frontiers in Evolutionary Neuroscience, 4, 14. 
Eco, U. (1986). Art and Beauty in the Middle Ages. New Haven and London: Yale University Press.

Fink, B., \& Penton-Voak, I. (2002). Evolutionary psychology of facial attractiveness. Current Directions in Psychological Science, 11, 154-158.

Fisher, R.A. (1915). The evolution of sexual preference. Eugenics Review, 7, 184-192. Gangestad, S.W., \& Scheyd, G.J. (2005). The evolution of human physical attractiveness. Annual Review of Anthropology, 14, 523-548.

Gold, B.P., Mas-Herrero, E., Zeighami, Y., Benovoy, M., Dagher, Al., \& Zatorre, R.J. (2019). Musical reward prediction errors engage the nucleus accumbens and motivate learning. Proc. Natl. Acad. U.S.A., 116, 3310-3315.

Good, J.M., \& Nachman, M.W. (2005). Rates of protein evolution are positively correlated with developmental timing of expression during mouse spermatogenesis. Molecular Biology and Evolution, 22, 1044-1052.

Grammer, K., Fink, B., Møller, A.P., \& Thornhill, R. (2003). Darwinian aesthetics: sexual selection and the biology of beauty. Biological Reviews, 78, 385-407.

Hoke, K.L., Burmeister, S.S., Fernald, R.D., Rand,A.S., Ryan,M.J., \& Wilczynski, W. (2004). Functional mapping of the auditory midbrain during mate call reception. Journal of Neuroscience, 24, 11264-11272.

Johnston, V.S. (2005), Mate choice decisions: the role of facial beauty. Trends in Cognitive Sciences, 10, 9-13.

Jones, A.G., \& Rattermann, N.L. (2009). Mate choice and sexual selection: What have we learned since Darwin? Proceedings of the National Academy of Sciences, 106, 10001-10008.

Kirkpatrick, M., Rand, A.S., \& Ryan, M.J. (2006). Mate choice rules in animals. Animal Behaviour, 71, 1215-1225.

Kivy, P. (2003): The Seventh Sense (2. Ed). Oxford: Clarendon Press.

Kokko, H., Jennions, M.D., \& Brooks, R. (2006). Unifying and testing models of sexual selection. Annual Review of Ecology and Evolutionary Systems, 37, 4366.

Kuijper, B., Pen, I., \& Weissing, F.J. (2012). A guide to sexual selection theory. Annual Review of Ecology, Evolution, and Systematics, 41, 287-311.

Lane, N. (2010). Life Ascending. The Ten Great Inventions of Evolution. London: Profile Books. 
Langlois, J.H., Kalakanis,L., Rubenstein, A.J., Larson, A., Hallam, M., \& Smoot, M. (2000). Maxims or myths of beauty? A meta-analysis and theoretical review. Psychological Bulletin, 126, 390-423.

Lattin, C.R., Stabile, F.A., \& Carson, R.E. (2017). Estradiol modulates neural response to conspecific and heterospecific song in female house sparrows: An in vivo positron emission tomography study. PLOS ONE, 12, e 0182875.

LeDoux, J. (2012). Rethinking the emotional brain. Neuron, 73, 653-676.

Little, A.C., \& Jones, B.C. (2009). The evolutionary cognitive neuropsychology of face preferences. In S.M. Platek \& T.K. Shackelford (Eds.), Foundation in Evolutionary Cognitive Neuroscience (pp. 175-204). Cambrudge, UK:

Cambridge University Press.

Little, A.C., Jones, B.C., \& DeBruine, L.M. (2011). Facial attractiveness:

Evolutionary based research. Philosophical Transactions of the Royal Society of London B, 366, 1638-1659.

Lynch, K.S., Rand, A.S., Ryan, M.J, \& Wilczynski, W. (2005). Plasticity in female mate choice associated with changing reproductive states. Animal Behaviour, 69, 689-699.

Lynch, K.S, Crews, D., Ryan, M.J., \& Wilczynski (2006). Hormonal state influences aspects of female mate choice in the Túngara Frog (Physalaemus pustulosus). Hormones and Behavior, 49, 450-457.

Maney, D.L. (2013). The incentive salience of courtship vocalizations: Hormonemediated 'wanting' in the auditory system. Hearing Research, 305, 19-30.

Maney, D.L., Goode, C.T., Lange, H.S., Sanford, S.E., \& Solomon, B.L. (2008). Estradiol modulates neural responses to song in a seasonal songbird. The Journal of Comparative Neurology, 511, 173-186.

Patricelli, G.L., Hebets, E.A., \& Mendelson, T.C. (2018). Book review of Prum, R.O. 2018. The evolution of beauty. Evolution, 73, 115-124.

Paul, E.S., Sher, S., Tamietto, M., Winkielman, P., \& Mendl, M.T. (2020). Towards a comparative science of emotion: Affect and consciousness in humans and animals. Neuroscience and Biobehavioral Reviews, 108, 749-770.

Pessoa, L., Medina, L., Hof, P.R., \& Desfilis, E. (2019). Neural architecture of the vertebrate brain: implications for the interaction between emotion and cognition. Neuroscience and Biobehavioral Reviews, 107, 296-312. 
Prum, R.O. (2017). The Evolution of Beauty: How Darwin's Forgotten Theory of Mate Choice Shapes the Animal World - and Us. New York: Doubleday.

Puts, D.A. (2010). Beauty and the beast: mechanism of sexual selection in humans. Evolution and Human Behavior, 31, 157-173.

Rangel, A., Camerer, C., \& Montague, P.R. (2008). A framework for studying the neurobiology of value-based decision making. Nature Reviews Neuroscience, 9, 545-556.

Richards, E. (2017). Darwin and the Making of Sexual Selection. Chicago and London: The University of Chicago Press.

Rodd, F.H., Hughes, K.A., Grether, G.F., \& Baril, C.T. (2002). A possible non-sexual origin of mate preference: are male guppies mimicking fruit? Proceedings of the Royal Society of Biology B, 269, 475-81.

Rhodes, G. (2006). The evolutionary psychology of facial beauty. Annual Review of Psychology, 57, 199-226.

Ryan, M.J. (1990). Sensory systems, sexual selection, and sensory exploitation. Oxford Surveys in Evolutionary Biology, 7, 157-195.

Ryan, M.J. (2018). A Taste for the Beautiful. The Evolution of Attraction. Princeton \& Oxford: Princeton University Press.

Ryan, M.J., Bernal, X.E., \& Rand, A.S. (2010). Female mate choice and the potential for ornament evolution in túngara frogs, Physalaemus pustulosus. Current Zoology, 56, 343-357.

Ryan, M.J., \& Cummings, M.E. (2013). Perceptual biases and mate choice. Annual Review of Ecology, Evolution, and Systematics, 44, 437-459.

Ryan, M.J., \& Jordan, L.A. (2017). Courtship and mate choice. In J. Call et al. (Eds.), APA Handbook of Comparative Psychology, Vol. I (pp. 765-786).

Washington, DC: American Psychological Association.

Sakaki, M., \& Mather, M. (2012). How reward and emotional studies induce different reactions across the menstrual cycle. Social and Personality Psychology Compass, 6(1), 1-17.

Salimpoor, V. N., Benovoy, M., Larcher, K., Dagher, A., \& Zatorre, R. J. (2011). Anatomically distinct dopamine release during anticipation and experience of peak emotion to music. Nature Neuroscience, 14, 257-262.

Seymour, B., \& McClure, S.M. (2008). Anchors, scales and the relative coding of value in the brain. Current Opinion in Neurobiology, 22, 970-981. 
Skov, M. (2019a). Aesthetic appreciation: The view from neuroimaging. Empirical Studies of the Arts, 37, 220-248.

Skov, M. (2019b). The neurobiology of sensory valuation. In M. Nadal \& O. Vartanian (Eds.), The Oxford Handbook of Empirical Aesthetics (pp. 1-40). Oxford: Oxford University Press. DOI: 10.1093/oxfordhb/9780198824350.013.7

Skov, M., \& Nadal, M. (2019). The nature of perception and emotion in aesthetic appreciation: A response to Makin's challenge to Empirical Aesthetics. Psychology of Aesthetics, Creativity and the Arts. Advance first publication. DOI:10.1037/aca0000278

Skov \& Nadal, M. (2020): A farewell to art: Aesthetics as a topic in psychology and neuroscience. Perspectives on Psychological Science, 15, 630-642. DOI: $10.1177 / 1745691619897963$

Tatarkievicz, W. (1972). The great theory of beauty and its decline. The Journal of Aesthetics and Art Criticism, 31, 165-180.

Thornhill, R. (2003). Darwinian aesthetics informs traditional aesthetics. In E. Voland \& K. Grammer (Eds.), Evolutionary Aesthetics (pp. 9-35). Berlin: Springer. van den Bosch, I. Dalenberga, J.R., Renkena, R., van Langeveld, A.W.B., Smeets, P.A.M., Griffioen-Roose, S., ter Horsta, G.J., de Graaf, C., \& Boesveldt, S. (2014). To like or not to like: Neural substrates of subjective flavor preferences. Behavioural Brain Research, 269, 128-137.

Velez, A., Gall, M.D., \& Lucas, J.R. (2015). Seasonal plasticity in auditory processing of the envelope and temporal fine structure of sounds in three songbirds. Animal Behavior, 103, 53-63.

Wiens, J.J., \& Tuschhoff,E. (2020). Songs versus colours versus horns: What explains the diversity of sexually selected traits? Biological Reviews. Advance first publication. DOI: 10.1111/brv.12593

Yoest, K.E., Quigley, J.A., \& Becker, J.B. (2018). Rapid effects of ovarian hormones in dorsal striatum and nucleus accumbens. Hormones and Behavior, 98, 210218. 